\title{
Turbulence and high-frequency variability in a deep gravity current outflow
}

\author{
Jonathan D. Nash, ${ }^{1}$ Hartmut Peters, ${ }^{2}$ Samuel M. Kelly, ${ }^{1,3}$ Josep L. Pelegrí, ${ }^{4}$ \\ Mikhail Emelianov, ${ }^{4}$ and Marc Gasser ${ }^{4}$ \\ Received 27 June 2012; revised 13 August 2012; accepted 14 August 2012; published 28 September 2012.
}

[1] Intensive sampling of the deep Mediterranean outflow $70 \mathrm{~km} \mathrm{~W}$ of the Strait of Gibraltar reveals a strong, tidally modulated gravity current embedded with large-amplitude oscillations and energetic turbulence. The flow appears to be hydraulically controlled at a small topographic constriction, with turbulence and internal waves varying together and increasing dramatically downstream of the choke point. These data suggest that a significant fraction of energy dissipation, mixing, and entrainment stress in gravity currents may occur in localized regions controlled by time-varying flow interactions with fine-scale topography. These findings highlight the important role of processes that are not resolved by global climate models (GCMs), which do not contain tides or mixing due to fine-scale topographic interactions. Citation: Nash, J. D., H. Peters, S. M. Kelly, J. L. Pelegrí, M. Emelianov, and M. Gasser (2012), Turbulence and high-frequency variability in a deep gravity current outflow, Geophys. Res. Lett., 39, L18611, doi:10.1029/ 2012GL052899.

\section{Introduction}

[2] Gravity current overflows represent a major pathway for deep water replenishment, and thus play an important role in ocean circulation and climate predictions [Legg et al., 2009]. Since mixing controls the downstream evolution of $T$ and $S$, the equilibrated outflow's ultimate composition is controlled by upstream turbulence. Proper accounting of processes controlling cumulative entrainment is a prerequisite for predicting terminal depth and volume flux, properties that can dynamically alter global circulation patterns.

[3] The Mediterranean (Med) outflow represents the single largest source of warm, saline water to the deep Atlantic [Price et al., 1993], forming long-lived dynamical features like Meddies [Armi and Zenk, 1984] and influencing the Meridional Overturning Circulation [Reid, 1979; Bryden and Kinder, 1991; Wu et al., 2007]. Within the Strait of Gibraltar, the outflow is strongly tidal, varying from 0 to $2 \mathrm{~Sv}$ during a typical semidiurnal period [Bryden et al., 1994]. As the flow plunges into the Atlantic, shear instabilities form on the interfacial layer between Med and Atlantic waters, producing

\footnotetext{
${ }^{1}$ College of Earth, Ocean and Atmospheric Sciences, Oregon State University, Corvallis, Oregon, USA.

${ }^{2}$ Earth and Space Research, Seattle, Washington, USA.

${ }^{3}$ Oceans Institute, University of Western Australia, Crawley, Western Australia, Australia.

${ }^{4}$ Institut de Ciències del Mar, CSIC, Barcelona, Spain.

Corresponding author: J. D. Nash, College of Earth, Ocean and Atmospheric Sciences, Oregon State University, 104 CEOAS Admin Bldg., Corvallis, OR 97331, USA. (nash@coas.oregonstate.edu)

C2012. American Geophysical Union. All Rights Reserved. 0094-8276/12/2012GL052899
}

$>50-\mathrm{m}$ vertical undulations and turbulent kinetic energy dissipation rates $\epsilon$ of $10^{-4}-10^{-2} \mathrm{~W} / \mathrm{kg}$ during peak outflows [Wesson and Gregg, 1994]. This produces a dense, temporally modulated gravity current that flows into the Atlantic over a series of constrictions and sills before reaching geostrophic equilibrium and ultimately settling at a terminal depth around $1000 \mathrm{~m}$.

[4] Coupled hydraulic processes, turbulence and internal waves have been studied intensively in straits [e.g., Wesson and Gregg, 1994; Klymak and Gregg, 2004]. While turbulent mixing has been studied in outflows downstream from their source, much of the fine-scale and submesoscale spectrum has been largely ignored; studies of overflows in the Baltic Sea [Umlauf and Arneborg, 2009] and the Faroe Bank Channel [Fer et al., 2010; Seim and Fer, 2011] are notable exceptions.

[5] Turbulence in the Med outflow has been directly quantified during the 1988 Gulf of Cadiz experiment [Price et al., 1993]. That study revealed intense turbulence within the 150-m thick gravity current [Johnson et al., 1994a; Baringer and Price, 1997a] and permitted mixing and stress to be computed using bulk budgets [Johnson et al., 1994b; Baringer and Price, 1997b] (hereinafter JSB94 and BP97, respectively).

[6] BP97 and JSB94 produced several significant findings: (1) outflow transport more than doubled from $0.7 \mathrm{~Sv}$ at the Strait to $1.9 \mathrm{~Sv}$ at terminal depth due to entrainment, and (2) during the outflow's initial descent (in the vicinity of Spartel West Sill), bulk momentum budgets required $5 \pm$ $1 \mathrm{~Pa}$ of retarding stress, of which 1-2.5 Pa was supplied by bottom stress $\tau_{b}$. Estimates of the interfacial stress $\tau_{i}$ based on mean-flow gradients varied from $0.8 \pm 0.4 \mathrm{~Pa}$ (BP97) to 3-4 Pa (JSB94). Direct estimates of $\tau_{i}$ using shear probes were roughly $1 / 3$ of $\tau_{b}$ [Johnson et al., 1994a], and similar to BP97's estimates $(\leq 1 \mathrm{~Pa})$. BP97 attributed the discrepancies between total stress and $\tau_{i}+\tau_{b}$ to undersampling in both space and time. For example, of the 30 dissipation profiles in total, fewer than 10 exhibited $\left|\tau_{i}\right|>0.25 \mathrm{~Pa}$ or $\left|\tau_{b}\right|>1 \mathrm{~Pa}$ [Johnson et al., 1994a], and tidal variability was not resolved. To summarize the above findings, BP97 suggest the total retarding stress to be well constrained (weakening from 3 to $5 \mathrm{~Pa}$ near the Strait to $<0.5 \mathrm{~Pa}$ further downstream), and that $\tau_{b}$ appears to exceed $\tau_{i}$; however JSB94's finding that $\left|\tau_{i}\right| \approx 4 \pm 1 \mathrm{~Pa}$ over a $20 \mathrm{~km}$ region near Spartel Sill West hints toward a possibility that interfacial stresses could be locally higher.

[7] In the following we investigate the roles of time-dependent and/or interfacial processes associated with flow over small-scale topography in generating the large $\tau_{i}$ observed by JSB94 and implied by the total stress required (JSB94, BP97). Highly resolved transects and time series were obtained across 


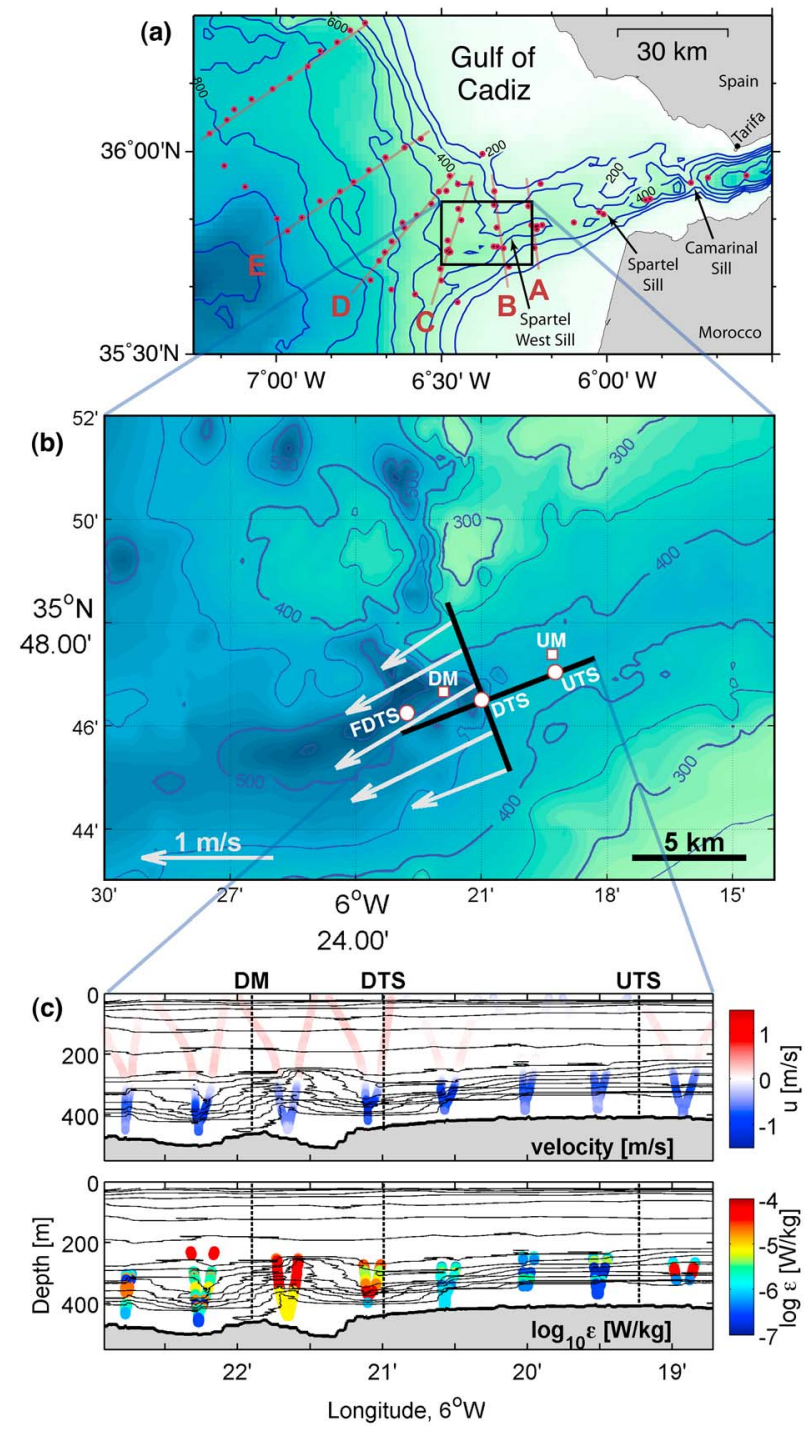

Figure 1. (a) Observational setting and BP97 survey lines. (b) Detailed bathymetry of the Spartel West Sill showing locations of repeat shipboard transects (black), time series stations (UTS,DTS,FDTS), and moorings (UM,DM); white vectors show tidally averaged velocity, $100 \mathrm{~m}$ above bottom $\left(u_{100}\right)$. (c) An example yo-yo transect (10-Jul-2009, 0150-0400 UTC) shows (top) along-axis velocity and (bottom) $\log _{10} \epsilon$; density is contoured. Bathymetry represents a composite from GEBCO (www.gebco.net) [Zitellini et al., 2009] and singleping echosounder data from this study, gridded at $100 \mathrm{~m}$.

Spartel West Sill (section B in BP97's Figure 6b and reproduced here in Figure 1a). At this location, BP97 observed the Med Outflow's largest decrease in momentum, which far exceeded the measured bottom stress $\tau_{b}$. We hypothesize that fine-scale processes are responsible for elevated interfacial turbulence, and test this through analysis of tidal, hydraulic and high-frequency dynamics at the Spartel West Sill.

\section{Setting and Measurements}

[8] The Spartel West Sill is a mild topographic constriction at the west end of Tangier Basin, approximately $20 \mathrm{~km}$ west of the main Spartel Sill (Figure 1). This relatively gentle sill at $420-\mathrm{m}$ depth channels the outflow within a $6-\mathrm{km}$ span before it plunges into a rough 500-m deep depression in $\mathrm{O}(1 \mathrm{~km})$. The flow encounters significant bathymetric complexity before it exits this topographic confinement and begins its inertial turn North.

[9] In July 2009, 418 profiles of velocity and density were obtained from LADCP/CTD (lowered acoustic Doppler current profiler; dual $300 \mathrm{kHz}$ RD-Instruments). Seventeen along-stream and four cross-stream transects were acquired while the $\mathrm{R} / \mathrm{V}$ García del Cid steamed at 1.2-1.8 knots. Transects were repeated at 3-h intervals. The LADCP/CTD profiled from surface to bottom, resolving tidal variability with 500-1000 m horizontal resolution over a 6-8 km span (Figure 1c; see also Gasser et al. [2011] for an overview). LADCP data were processed following the methods outlined in Firing and Gordon [1990] and Peters et al. [2005]. Shipboard $75 \mathrm{kHz}$ ADCP captured the top of the outflow, providing a strong constraint on the LADCP solution.

[10] Also acquired were two 12-h fixed-station time series upstream (UTS; $6^{\circ} 19.23^{\prime} \mathrm{W}, 35^{\circ} 47.04^{\prime} \mathrm{N}$ ), two $12-24$-h time series downstream (DTS; $6^{\circ} 21.00^{\prime} \mathrm{W}, 35^{\circ} 46.51^{\prime} \mathrm{N}$ ), and one 12-h time series far downstream (FDTS; $6^{\circ} 22.79^{\prime} \mathrm{W}$, $35^{\circ} 46.25^{\prime} \mathrm{N}$ ). Some time series were acquired by alternating short, deep yoyos (within 200-m of the bottom) with full-depth casts, yielding 20-min spacing between casts. Moorings were deployed near the sill crest (Upstream Mooring; UM) and $5 \mathrm{~km}$ downstream in the $500 \mathrm{~m}$ depression (Downstream Mooring; DM; Figure 1). Unfortunately, DM broke free $30 \mathrm{~h}$ into the deployment, so we focus on data from UM, where two T-chains, two Sontek ADPs ( $250 \mathrm{kHz}$ down-looking, $500 \mathrm{kHz}$ up-looking), 2 CTDs and a RCM- 8 current meter span the bottom $250 \mathrm{~m}$; sensor locations are indicated in Figure $2 \mathrm{~b}$.

[11] In the following, we define "along-stream" as parallel to our main transect, which is oriented $20^{\circ} \mathrm{N}$ of $\mathrm{E}$, includes UTS and DTS, and has origin at DTS. Potential density $\sigma$ is referenced to $300 \mathrm{~m}, N^{2}$ is the stably resorted stratification, and $S^{2}$ represents the square of velocity shear, computed over $8-\mathrm{m}$ intervals. Turbulent dissipation rates were inferred from Thorpe analysis of unstable- $\sigma$ overturns as $\epsilon=0.64 L_{T}^{2} N^{3}$ [Dillon, 1982], where $L_{T}$ represents the RMS Thorpe displacement within each patch, defined after applying run-length and overturn size criteria [Finnigan et al., 2002]. Turbulent diffusivities of mass and momentum were computed assuming a constant mixing efficiency $\Gamma$ as $K_{\rho}=0.2 \epsilon / N^{2}$ and $K_{m}=1.2 \epsilon / S^{2}$; while $\Gamma$ is likely to be variable, Gregg et al. [2012] provide a discussion and justification for this choice of $\Gamma=0.2$.

\section{Observations}

[12] A typical yo-yo transect is shown in Figure 1c. At this time, a weak return flow above $250 \mathrm{~m}(u=$ pink, eastward $)$ opposes the $>1 \mathrm{~ms}^{-1}$ deep outflow in the bottom $150 \mathrm{~m}(u=$ blue, westward). Upstream (near UTS), isopycnals gradually descend and the flow thins and accelerates toward DTS; inferred turbulent dissipation is weak. Downstream (near DTS and DM), deep isopycnals rebound abruptly, velocity shows strong variability from cast to cast, and $30-50 \mathrm{~m}$ density overturns were observed. Downstream of DTS, $\epsilon>10^{-5} \mathrm{~W} / \mathrm{kg}$ and $K_{m} \approx K_{\rho} \approx 1 \mathrm{~m}^{2} / \mathrm{s}$, about 100 times larger than upstream. In addition, up and down CTD casts (obtained within 10 min of 

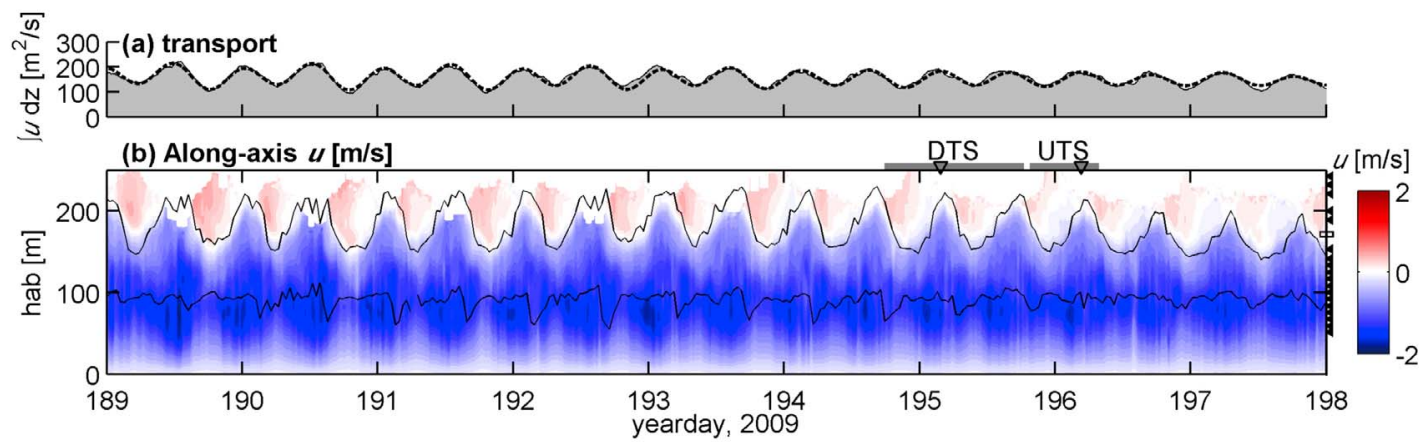

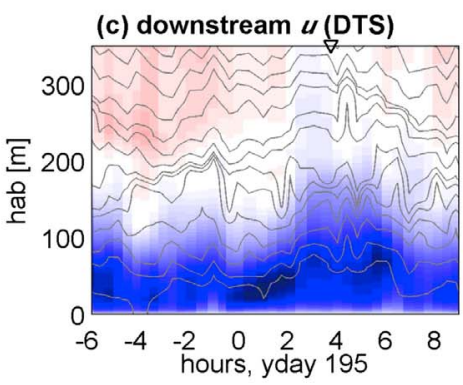

(g) downstream $\varepsilon$

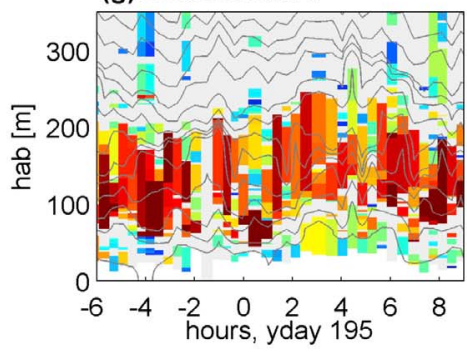

(d) upstream $u$ (UTS)

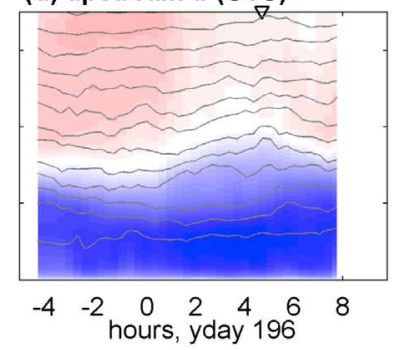

(h) upstream $\varepsilon$

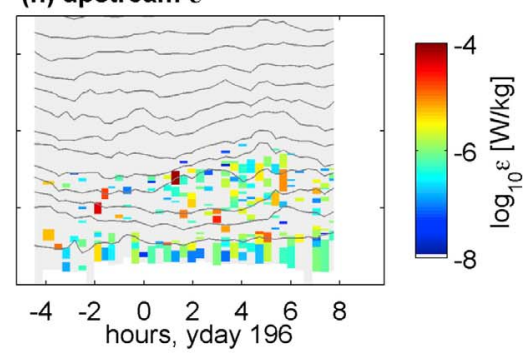

(e) tidal $\xi$

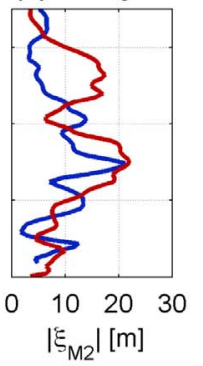

(f) high-f $\xi$

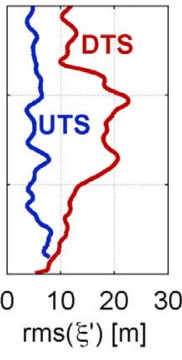

Figure 2. Tidal variability of (a) transport (b) vertical structure of along-stream velocity from ADPs at UM, with the 13.5 and $14^{\circ} \mathrm{C}$ isotherms contoured (the latter approximately bounds westward flow). (c, d) 15-h records of LADCP velocity (colors) and isopycnals (contours) at UTS and DTS for the periods indicated in Figure 2b; panels have been aligned to represent the same range of tidal phase (open triangles denote time of maximum transport). (e) Tidal and (f) high-frequency $\xi$ at UTS and DTS. $(\mathrm{g}, \mathrm{h}) \epsilon$ from unstable overturns. Note: hab denotes height above bottom. Also indicated to the right of Figure $2 \mathrm{~b}$ are the locations of T/C loggers (solid triangles) and $500 \mathrm{kHz}$ upward and $250 \mathrm{kHz}$ downward ADPs (open squares).

each other) often exhibited 30-50 m differences in isopycnal displacement $\xi-$ similar to $L_{T}$. Note that $2 \pi / N \sim 10 \mathrm{~min}$.

[13] This instantaneous snapshot has qualitative similarities to that of a hydraulically controlled flow, whereby a relatively quiescent upstreamflow accelerates downhill, becomes highly turbulent and abruptly transitions back to a subcritical state further downstream in a hydraulic jump or breaking lee-wave [e.g., Armi, 1986].

[14] Following Peters et al. [2005], we compute the Froude number $\left(F r=U_{p} / \sqrt{g^{\prime} H_{p}}\right)$ as the ratio of the outflow velocity $U_{p}$ to a wave speed computed from reduced gravity $g^{\prime}$ and plume thickness $H_{p}$ relative to the overlying strata; here $H_{p}$ is defined based on a density criterion as detailed in Peters et al. [2005]. From this definition of Fr, the upstream flow is subcritical (mean $F r=0.81$ ) and exhibits little variability $(90 \%$ of $F r$ fall between 0.70 and 0.92 ). In contrast, downstream at DTS, the mean $F r=0.99$, and $45 \%$ of profiles exhibit $F r>1$. Variability is also increased downstream, with $90 \%$ of estimates spanning the range $0.63<F r<1.45$ at DTS. This is consistent with a transitional flow with a hydraulic control point (i.e., $F r=1$ ) near or upstream of DTS, an accelerated flow $(F r>1)$ downstream of the control, and an ultimate rebound to $F r<1$ farther downstream. Application of the Taylor-Goldstein equation with shear indicates the flow is unstable to shear instability, implicating Kelvin-Helmholtz instability as another possible source of the observed undulations and turbulence [Smyth et al., 2011].

\subsection{Tidal Variability}

[15] Temporal variability is dominated by the semidiurnal tide (Figure 2b), which produces 40-60 m peak-to-peak changes in outflow thickness $H_{p}$ and $0.5 \mathrm{~m} \mathrm{~s}^{-1}$ changes in $u$ at UM. Because $H_{p}$ and $u$ co-vary, tides modulate Med outflow transport by $\pm 35 \%$ (Figure $2 \mathrm{a}$ ). Here, transport is computed as the vertical integral of $u$ from the bottom to the height where $u$ reverses, which approximately corresponds to the height of the $14^{\circ}$ isotherm.

[16] Downstream and upstream locations exhibit a similar magnitude of tidal isopycnal displacements (compare DTS and UTS in Figure 2e), although they extend farther from the bottom at DTS. Tidal modulation also alters the location of 


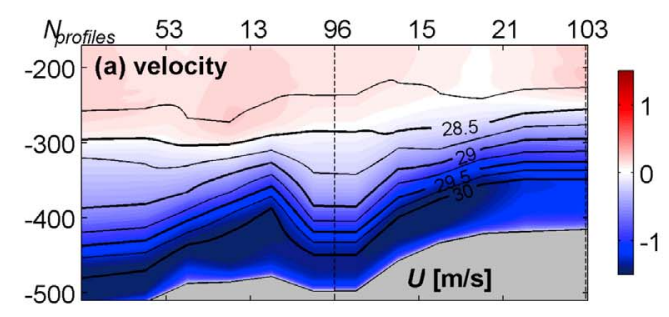

(b) high-freq energy
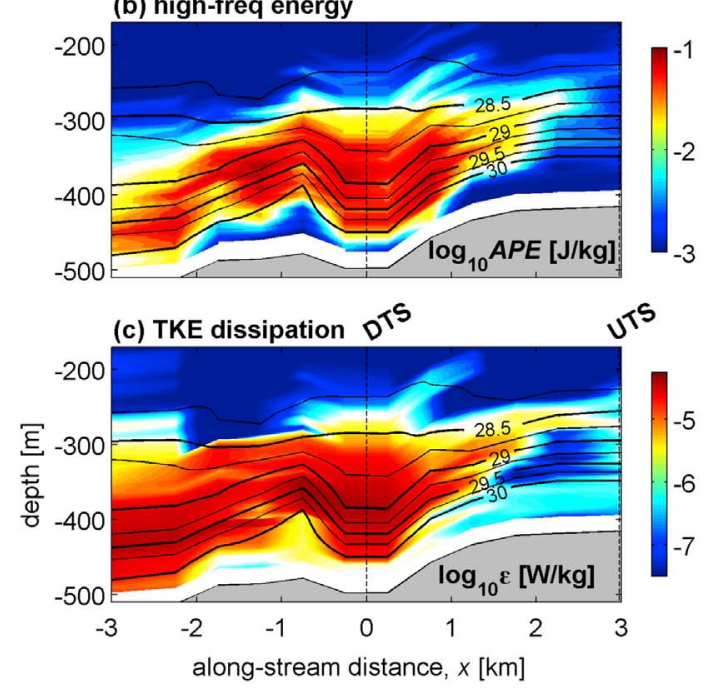
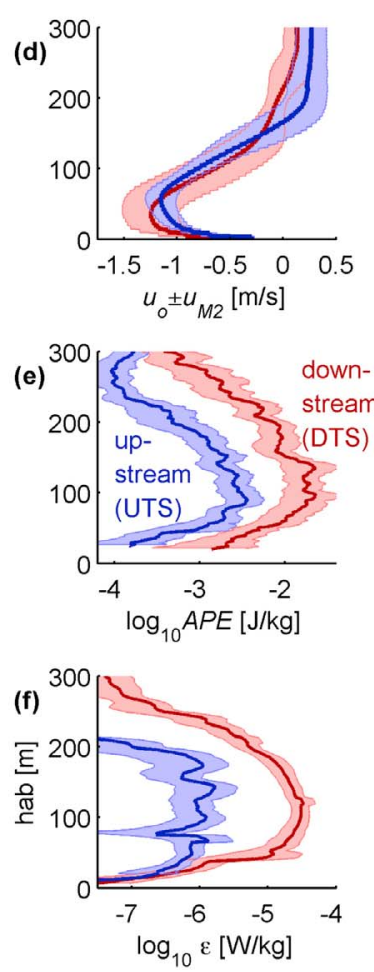

(g) occurrence

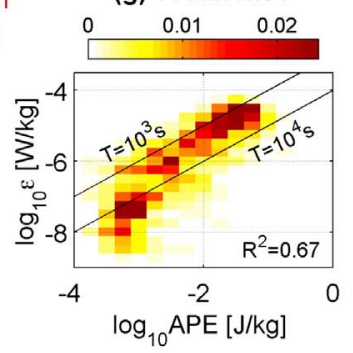

Figure 3. Mean along-stream transects of (a) along-axis velocity, (b) super-tidal $A P E$, and (c) inferred $\epsilon$; $\sigma$ is contoured. Data were horizontally binned in 1-km, half-overlapping bins and vertically with respect to height above the bottom; the number of profiles $N_{\text {profiles }}$ in each independent horizontal bin is indicated above Figure 3a. Also shown are timeaveraged profiles of (d) $u_{o}$ and its tidal range $\pm u_{M 2}$ in shading, (e) $A P E$, and (f) $\epsilon$ at stations UTS (blue) and DTS (red). (g) A 2-dimensional histogram of the data from Figures $3 b$ and $3 c$; redder points occur more frequently. Shading in Figures $3 \mathrm{e}$ and 3 f represent $95 \%$ bootstrap confidence limits.

high $\epsilon$ regions - which track isopycnals (and shear) and shift $\pm 20 \mathrm{~m}$ vertically with the tides.

[17] The strong temporal modulation of $u$ and $H_{p}$ has consequences for estimates of stress based on steady-flow assumptions (JSB94, BP97). Since terms in the momentum budget scale with $u^{2}$ (as does the expected turbulent stress), we anticipate that tidal aliasing introduces $\pm 35 \%$ uncertainty into calculations based on a single realization. Moreover, entrainment rates computed from bulk budgets depend on differences in fluxes, so uncertainties due to unresolved tides are further amplified in these higher-order calculations.

\subsection{High-Frequency Waves and Dissipation}

[18] In the following, the high-frequency variation in isopycnal displacement $\xi^{\prime}$ (Figures 2c-2f) is used to estimate internal-wave energy. First, $\sigma$ is Thorpe-resorted and $\xi(\sigma)$ computed as the distance a water parcel of density $\sigma$ is vertically displaced from its mean depth. Then, a tidal harmonic analysis is performed at each depth to minimize the residual $\xi^{\prime}$ in a least squares sense: $\xi(t)=\xi_{o}+\operatorname{Re}\left\{\xi_{M 2} \exp (i \omega t)\right\}+\xi^{\prime}$ (t). Here, $\omega=2 \pi / 12.42 \mathrm{~h}$ is the semidiurnal tidal frequency, $\xi_{M 2}$ is the complex tidal amplitude, and $\xi_{o}$ is the mean isopycnal displacement, which is $\neq 0$ for irregularly sampled time series. The quantity being minimized represents the available potential energy associated with supertidal displacement variance: $A P E=\left\langle\xi^{2}\right\rangle N^{2} / 2$.
[19] Harmonic analyses were performed independently within each time series period (at UTS, DTS and FDTS; 230 casts in total), which reduces variance aliased into $\xi^{\prime}$. From the example time series in Figures $2 \mathrm{c}$ and $2 \mathrm{~d}$, there are dramatic differences in $\xi^{\prime}$ variance between UTS and DTS, with $\operatorname{RMS}\left(\xi^{\prime}\right)$ increasing from $\sim 5 \mathrm{~m}$ upstream to $>20 \mathrm{~m}$ downstream (Figure 2f). Commensurate with the increase in $A P E$ is a 10 to 100 -fold increase in $\epsilon$ (Figures $2 \mathrm{~g}$ and $2 \mathrm{~h}$ ).

[20] In addition, data from the 17 along-stream transects were used to compute the spatial pattern of APE. Profiles were grouped into half-overlapping $1 \mathrm{~km}$ wide bins and harmonic analyses performed by treating each bin as a time series consisting of 13-103 profiles with $<3$-h nominal sampling (Figure 3). High-frequency fluctuations are thus aliased into each record and the residual to each fit represents the signal of interest. Tests performed by subsampling DTS time series indicate $A P E$ computed in this manner is not substantially biased.

[21] Transect and station data are combined to produce a composite of the mean along-axis structure of potential density, along-stream velocity, high-frequency $A P E$ and $\epsilon$ (Figures $3 \mathrm{a}-3 \mathrm{c}$ ). Evident from the velocity and density is a strongly undulating deep current, characteristic of an accelerated downslope flow and hydraulic jump or arrested leewave. Above this, isopycnals vary smoothly and a weak eastward return flow toward the Mediterranean exists. Between 

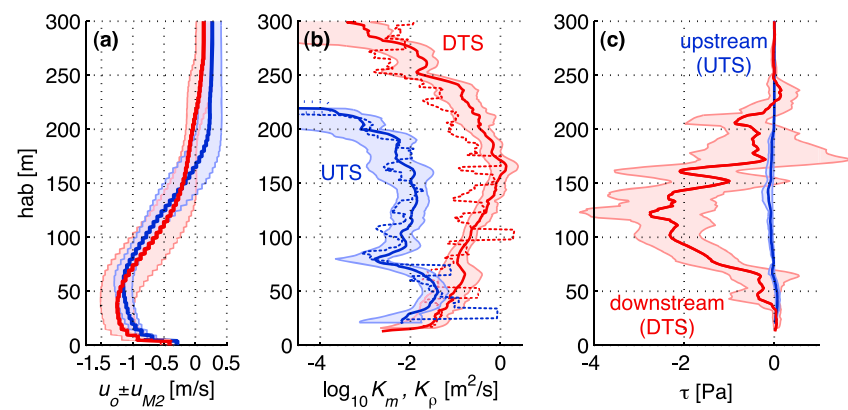

Figure 4. Turbulent mixing and stress at upstream (blue) and downstream (red) time series stations. (a) Mean (lines) and tidal (shaded envelope) velocity. (b) Eddy diffusivities for momentum ( $K_{m}$; solid) and mass $\left(K_{\rho}\right.$; dashed). (c) Turbulent stress. Shading in Figures $4 \mathrm{~b}$ and $4 \mathrm{c}$ represent $95 \%$ bootstrap confidence limits on $K_{m}$ and $\tau$.

these two layers is a region of strong shear and stratification. Note that bottom boundary layer turbulence is not estimated because (1) measurements often did not include the bottom $30 \mathrm{~m}$, and (2) Thorpe analyses are not effective in well-mixed boundary layers.

[22] Perturbation $A P E$ and $\epsilon$ in the bottom $200 \mathrm{~m}$ increase dramatically as the flow-passes over the sill crest (near UTS) and plunges downslope past DTS. Both quantities have a similar spatial structure and their logarithms are highly correlated (Figure 3g), suggesting that the turbulence is driven by breaking internal waves [D'Asaro and Lien, 2000]. The timescale for turbulent decay $(T=A P E / \epsilon)$, is typically $\sim 10^{3} \mathrm{~s}$ in regions of strong turbulence, which represents several buoyancy periods $(2 \pi / N \sim 500 \mathrm{~s})$ and implies a spatial decay of a few kilometers. Thus, distinct wave-like undulations may exist, but these are difficult to identify because they have similar timescale as our profile spacing. The undulating disturbances reported here have decay scales similar to oscillations observed in the equatorial undercurrent [Moum et al., 2011], which were interpreted as shear instabilities of the mean flow by Smyth et al. [2011]. Similar stability analyses performed on these data indicate the Med is also susceptible to high-frequency wave growth (B. Smyth, personal communication, 2012). It is thus possible the correlation between $\epsilon$ and $A P E$ indicates that the observed $A P E$ is associated with breaking shear instability waves that generate the turbulence. However, we also note significant differences between the Med outflow and the equatorial undercurrent, namely the Med outflow has higher $\epsilon$ and $A P E$ and appears to be topographically controlled, which can lead directly to breaking lee waves [Farmer and Smith, 1980].

\subsection{Mixing and Stress}

[23] The intense wave activity that develops downstream of Spartel West Sill increases $A P E$ and $\epsilon$ by a factor of 10 100. As a result, inferred turbulent diffusivities for mass and momentum increase by a similar factor in the strongly sheared interface region between outflow and Atlantic waters, peaking at $K_{m} \approx K_{\rho} \approx 1 \mathrm{~m}^{2} / \mathrm{s}$ (Figure $4 \mathrm{~b}$ ). This results in significant upward transport of westward momentum, as quantified by $\tau=K_{m} \partial u / \partial z$. Upstream of the sill (at UTS), $\tau \approx-0.1 \pm 0.1 \mathrm{~Pa}$, while downstream (near DTS), $\tau \approx-2 \pm 1.0 \mathrm{~Pa}$ throughout the almost $100-\mathrm{m}$ thick interface (Figure 4c). Thorpe-based stress estimates cannot resolve $\tau$ in the well-mixed bottom boundary layer (e.g., within $50 \mathrm{~m}$ of the bottom). However, based on the direct measurements of Johnson et al. [1994a] and the sign of velocity shear, we anticipate $\tau_{b}$ to be positive and similar in magnitude to those reported above.

\section{Conclusions and Implications}

[24] Detailed observations at the Spartel West Sill reveal a gravity current that is both (i) highly unsteady over tidal through internal wave timescales, and (ii) spatially variable, with abrupt changes in stress by a factor of 10-100 over $1-\mathrm{km}$ scales. Hydraulic control by small-scale topography appears responsible for this inhomogeneity and the enhanced internal stress. This picture compliments large-scale estimates of the cumulative entrainment and retarding stress in historic studies [Price et al., 1993; JSB94; BP97] and regional modeling efforts [Xu et al., 2007].

[25] Our observations provide further insight into the role of interfacial stress in the initial descent of the outflow and help somewhat to reconcile the contrasting findings of previous studies. For example, direct estimates of $\tau_{i}$ near this sill by Johnson et al. [1994a] exceeded a magnitude of $1 \mathrm{~Pa}$ during only a single profile $\left(\tau_{i}=-3.25 \mathrm{~Pa}\right.$ during XDP drop 804 ), and averaged $-0.4 \mathrm{~Pa}$ in this area (across their lines $\mathrm{B}$ and $\mathrm{C}$ and stations 4 and 8). While similar to BP97's estimates from bulk entrainment rates $\left(\tau_{i} \sim-1 \mathrm{~Pa}\right)$, the measured $\tau_{i}$ contrasts the substantially greater bulk estimates of JSB94 ( -3 to $-4 \mathrm{~Pa})$.

[26] Here we find time-averaged $\tau_{i}=-2 \pm 1 \mathrm{~Pa}$ within the hydraulic jump region (at DTS) but only $\tau_{i}=-0.1 \pm 0.1 \mathrm{~Pa}$ upstream (at UTS), consistent with the wide distribution of previous $\tau_{i}$ estimates reported above. It is thus plausible that the Med outflow's initial descent may be strongly influenced by high interfacial stresses that act on the large-scale momentum (JSB94, BP97) but were not captured by Johnson et al. [1994a] because of their localized nature. Multibeam bathymetry [Zitellini et al., 2009] indicates the Gulf of Cadiz is incised with a spectrum of roughness down to $\mathrm{O}(1 \mathrm{~km})$ scales, so intensified dynamics may impact more than just the major sills indicated in Figure 1a. Within the Strait of Gibraltar, for example, hydraulic control and large-amplitude shear instabilities produce $\epsilon \approx 10^{-2} \mathrm{~W} / \mathrm{kg}$ at Camarinal Sill, 100x larger than those observed here [Wesson and Gregg, 1994].

[27] While our observations indicate that $\tau_{i}$ is significant, our data do not permit us to compare this directly to $\tau_{b}$. However, it is likely that the ratio of $\tau_{i}$ to $\tau_{b}$ is strongly variable and controlled by topography. Whereas $\tau_{b}$ may be quasihomogeneous (as it scales with $u^{2}$ ), $\tau_{i}$ depends on the internal flow stability, and can change abruptly as a flow transitions from marginally stable to marginally unstable (from UTS to DTS). Like the equatorial undercurrent, the mean state of the Med outflow has Richardson number close to $1 / 4$, so that small changes in background state can manifest into significant changes in mixing [Moum et al., 2009].

[28] We suggest that the Med Outflow acts like a pool and drop river, whereby the outflow transitions abruptly from a marginally stable, relatively quiescent flow into intense undulations and turbulence. Based on the complexity of the topography [Zitellini et al., 2009], we contend that a large fraction of the Med's mixing may occur within accelerated downslope flows that enhance $\epsilon, K_{m}$ and $K_{\rho}$ by a factor 
of 100, and produce order-of-magnitude increases in $\tau$. Farther downstream (Figure 1a; BP97's sections D and E), largescale budgets indicate a weakening of the total stress to $\sim 0.5 \mathrm{~Pa}$ (BP97), consistent with a reduction in $\epsilon, K_{m}$ and $K_{\rho}$ as the Med approaches geostrophic equilibrium over the broad continental slope. However, the total entrainment remains substantial during much of the $140 \mathrm{~km}$ from Camarinal Sill [Baringer and Price, 1997a], indicating continued mixing during the Med's descent to terminal depth. Whether fine-scale topographic effects control the cumulative entrainment farther downstream remains an open question. In any event, numerical prediction of the Med's ultimate composition will likely require resolving or parameterizing the effect of turbulent dynamics over $\mathrm{O}(1 \mathrm{~km})$ scale topographic features [Özgökmen and Fischer, 2008].

[29] There is increasing evidence that the composition of Mediterranean Outflow waters have been changing on decadal timescales [Millot et al., 2006]. It has been suggested that anthropogenic changes may lead to a warmer and less dense Med Outflow [Thorpe and Bigg, 2000]. Because mixing is sensitive to subtle changes in flow stability, it is unlikely that numerical models that use "tuned" mixing parameterizations will adequately model bulk entrainment correctly under future scenarios where the outflow interacts differently with topographic complexity. It is thus imperative that the effects of fine-scale topographic roughness be captured or accurately parameterized in GCMs [e.g., Özgökmen et al., 2004] to avoid significant errors in climate predictions [Legg et al., 2009].

[30] Acknowledgments. We thank Joaquin Salvador, Maribel Lloret, Ray Kreth and Mike Neeley-Brown for their technical expertise, Jesus Garcìa-Lafuente, Murray Levine, and Ed Dever for sharing mooring instrumentation, Bill Smyth for his instability insights, and the Captain and crew of the R/V Garcì del Cid for their skillful operations at sea. Thoughtful comments on a previous version of the manuscript were provided by Greg Johnson and an anonymous reviewer. Eulàlia Gràcia of Unitat de Tecnología Marina, Barcelona, kindly provided us with processed multibeam depth data from the Gulf of Cadiz. Assistance by Andreas Thurnherr with LADCP processing is gratefully acknowledged. This work was supported by the U.S. National Science Foundation, grants OCE-0825287, OCE-0825297, and the Spanish Ministerio de Ciencia e Innovación, grants CTM2008-06438C02-01 and CTM2008-03422-E/MAR.

[31] The Editor thanks two anonymous reviewers for assistance evaluating this paper.

\section{References}

Armi, L. (1986), The hydraulics of two flowing layers with different densities, J. Fluid Mech., 163, 27-58, doi:10.1017/S0022112086002197.

Armi, L., and W. Zenk (1984), Large lenses of highly saline Mediterranean water, J. Phys. Oceanogr., 14, 1560-1576, doi:10.1175/1520-0485 (1984)014<1560:LLOHSM $>2.0$.CO;2.

Baringer, M. O., and J. F. Price (1997a), Mixing and spreading of the Mediterranean outflow, J. Phys. Oceanogr., 27, 1654-1677, doi:10.1175/ 1520-0485(1997)027<1654:MASOTM >2.0.CO;2.

Baringer, M. O., and J. F. Price (1997b), Momentum and energy balance of the Mediterranean outflow, J. Phys. Oceanogr., 27, 1678-1692, doi:10.1175/1520-0485(1997)027<1678:MAEBOT>2.0.CO;2.

Bryden, H. L., and T. H. Kinder (1991), Steady two-layer exchange through the Strait of Gibraltar, Deep Sea Res., 38, 445-463.

Bryden, H. L., J. Candela, and T. H. Kinder (1994), Exchange through the Strait of Gibraltar, Prog. Oceanogr., 33, 201-248, doi:10.1016/00796611(94)90028-0.

D'Asaro, E. A., and R. C. Lien (2000), The wave-turbulence transition for stratified flows, J. Phys. Oceanogr., 30, 1669-1678, doi:10.1175/15200485(2000)030<1669:TWTTFS $>2.0$.CO;2.

Dillon, T. M. (1982), Vertical overturns: A comparison of Thorpe and Ozmidov length scales, J. Geophys. Res., 87, 9601-9613, doi:10.1029/ JC087iC12p09601.

Farmer, D. M., and J. D. Smith (1980), Tidal interaction of stratified flow with a sill in Knight Inlet, Deep Sea Res., Part A, 27, 239-254, doi:10.1016/0198-0149(80)90015-1.
Fer, I., G. Voet, K. S. Seim, B. Rudels, and K. Latarius (2010), Intense mixing of the Faroe Bank Channel overflow, Geophys. Res. Lett., 37, L02604, doi:10.1029/2009GL041924.

Finnigan, T., D. Luther, and R. Lukas (2002), Observations of enhanced diapycnal mixing near the Hawaiian Ridge, J. Phys. Oceanogr., 32, 2988-3002, doi:10.1175/1520-0485(2002)032<2988:OOEDMN >2.0.CO;2.

Firing, E., and R. Gordon (1990), Deep ocean acoustic Doppler current profiling, in Proceedings of the IEEE Fourth Working Conference on Current Measurements, pp. 192-201, Inst. of Electr. and Electron. Eng., Piscataway, N. J.

Gasser, M., J. L. Pelegrí, J. D. Nash, H. Peters, and J. García-Lafuente (2011), Topographic control on the nascent Mediterranean outflow, Geo Mar. Lett., 31, 301-314, doi:10.1007/s00367-011-0255-x.

Gregg, M. C., M. H. Alford, H. Kontoyiannis, V. Zervakis, and D. Winkel (2012), Mixing over the steep side of the Cycladic Plateau in the Aegean Sea, J. Mar. Syst., 89, 30-47, doi:10.1016/j.jmarsys.2011.07.009.

Johnson, G. C., R. G. Lueck, and T. B. Sanford (1994a), Stress on the Mediterranean outflow plume: Part II. Turbulence and shear measurements, J. Phys. Oceanogr., 24, 2084-2092, doi:10.1175/1520-0485 (1994)024<2084:SOTMOP >2.0.CO;2.

Johnson, G., T. Sanford, and M. Baringer (1994b), Stress on the Mediterranean outflow plume: Part I. Velocity and water property measurements, J. Phys. Oceanogr., 24, 2072-2083, doi:10.1175/1520-0485(1994) 024<2072:SOTMOP $>2.0 . \mathrm{CO} ; 2$.

Klymak, J. M., and M. C. Gregg (2004), Tidally generated turbulence over the Knight Inlet sill, J. Phys. Oceanogr., 34, 1135-1151, doi:10.1175/ 1520-0485(2004)034<1135:TGTOTK $>2.0$. CO;2

Legg, S., et al. (2009), Improving oceanic overflow representation in climate models: The Gravity Current Entrainment Climate Process Team, Bull. Am. Meteorol. Soc., 90, 657-670, doi:10.1175/2008BAMS2667.1.

Millot, C., J. Candela, J. Fuda, and Y. Tber (2006), Large warming and salinification of the Mediterranean outflow due to changes in its composition, Deep Sea Res., Part I, 53, 656-666, doi:10.1016/j.dsr.2005.12.017.

Moum, J. N., R.-C. Lien, A. Perlin, J. D. Nash, M. C. Gregg, and P. J. Wiles (2009), Sea surface cooling at the equator by subsurface mixing in tropical instability waves, Nat. Geosci., 2, 761-765, doi:10.1038/ngeo657.

Moum, J. N., J. D. Nash, and W. D. Smyth (2011), Narrowband oscillations in the upper equatorial ocean. Part I: Interpretation as shear instabilities, J. Phys. Oceanogr., 41, 397-411, doi:10.1175/2010JPO4450.1.

Özgökmen, T. M., and P. F. Fischer (2008), On the role of bottom roughness in overflows, Ocean Modell., 20, 336-361, doi:10.1016/j. ocemod.2007.10.004.

Özgökmen, T., P. Fischer, J. Duan, and T. Iliescu (2004), Entrainment in bottom gravity currents over complex topography from three-dimensional nonhydrostatic simulations, Geophys. Res. Lett., 31, L13212, doi:10.1029/ 2004GL020186.

Peters, H., W. E. Johns, A. S. Bower, and D. M. Fratantoni (2005), Mixing and entrainment in the Red Sea outflow plume. Part I: Plume structure, J. Phys. Oceanogr., 35, 569-583, doi:10.1175/JPO2679.1.

Price, J., M. Baringer, R. Lueck, G. C. Johnson, I. Ambar, G. Parrilla, A. Cantos, M. A. Kennelly, and T. Sanford (1993), Mediterranean outflow mixing and dynamics, Science, 259, 1277-1282, doi:10.1126/ science.259.5099.1277.

Reid, J. L. (1979), On the contribution of the Mediterranean Sea outflow to the Norwegian-Greenland Sea, Deep Sea Res., Part A, 26, 1199-1223, doi:10.1016/0198-0149(79)90064-5.

Seim, K. S., and I. Fer (2011), Mixing in the stratified interface of the Faroe Bank Channel overflow: The role of transverse circulation and internal waves, J. Geophys. Res., 116, C07022, doi:10.1029/2010JC006805.

Smyth, W. D., J. N. Moum, and J. D. Nash (2011), Narrowband oscillations in the upper equatorial ocean. Part II: Properties of shear instabilities, J. Phys. Oceanogr., 41, 412-428, doi:10.1175/2010JPO4451.1.

Thorpe, R. B., and G. R. Bigg (2000), Modelling the sensitivity of Mediterranean outflow to anthropogenically forced climate change, Clim. Dyn., 16, 355-368, doi: $10.1007 / \mathrm{s} 003820050333$.

Umlauf, L., and L. Arneborg (2009), Dynamics of rotating shallow gravity currents passing through a channel. Part I: Observation of transverse structure, J. Phys. Oceanogr., 39, 2385-2401, doi:10.1175/2009JPO4159.1.

Wesson, J. C., and M. C. Gregg (1994), Mixing at Camarinal Sill in the Strait of Gibraltar, J. Geophys. Res., 99, 9847-9878, doi:10.1029/ 94JC00256.

Wu, W., G. Danabasoglu, and W. G. Large (2007), On the effects of parameterized Mediterranean overflow on North Atlantic ocean circulation and climate, Ocean Modell., 19, 31-52, doi:10.1016/j.ocemod.2007.06.003.

$\mathrm{Xu}$, X., E. P. Chassignet, J. F. Price, T. M. Ozgokmen, and H. Peters (2007), A regional modeling study of the entraining Mediterranean outflow, J. Geophys. Res., 112, C12005, doi:10.1029/2007JC004145.

Zitellini, N., et al. (2009), The quest for the Africa-Eurasia plate boundary west of the Strait of Gibraltar, Earth Planet. Sci. Lett., 280, 13-50, doi:10.1016/j.eps1.2008.12.005 